\title{
A RARE CASE STUDY OF TORSION OF A NON-GRAVID UTERUS
}

\author{
Basnet $T^{1}$, Pant $P R^{2}$, Sharma $J^{2}$, Pokharel $A^{2}$
}

\section{Affiliation}

1. Department of Obstetrics and Gynecology, BPKIHS, Dharan, Nepal

2. Department of Obstetrics and Gynecology, TUTH, IOM, Kathmandu, Nepal

\section{ARTICLE INFO}

Article History

Received : 31 August, 2017

Accepted : 12 November, 2017

Published : 31 December, 2017

(c) Authors retain copyright and grant the journal right of first publication with the work simultaneously licensed under Creative Commons Attribution License CC - BY 4.0 that allows others to share the work with an acknowledgment of the work's authorship and initial publication in this journal.

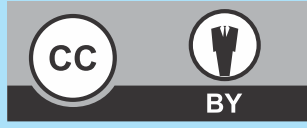

CR 15

DOI: http://dx.doi.org/10.3126/bjhs.v2i3.18954

\section{* Corresponding Author}

Dr. Tulasa Basnet

Senior Resident

Department of Obstetrics and Gynecology, BPKIHS, Dharan Email: tulasabasnet29@gmail.com

\section{Citation}

Basnet T, Pant PR, Sharma J, Pokharel A. A Rare Case Study of Torsion of a Non-gravid Uterus BJHS 2017;2(3)4 : 309-311

\section{ABSTRACT}

Torsion of a non gravid uterus is a rare but potentially fatal event. It may lead to rapid clinical deterioration causing irreversible ischemic damage to the uterus. The rarity of the condition and its non specific clinical presentation make the clinical diagnosis difficult. In this report we discuss a case of uterine torsion in a 55 year old postmenopausal lady who presented in emergency with acute abdomen. On examination a huge abdominal mass arising from pelvis was noted. The operative finding was huge fundal myoma with uterine torsion.

\section{KEY WORDS}

Ischemic, myoma, non-gravid, torsion 


\section{INTRODUCTION}

Torsion of the uterus is defined as rotation more than 45 degrees around the long axis. Torsion from 60 degrees to 720 degrees has been described. ${ }^{1}$ Most of the cases of uterine torsion have been described in a gravid state, whereby it results in serious maternal and fetal consequences. In a nongravid uterus the torsion results from uterine leiomyomas, mullerian anomalies, pelvic adhesion and the laxity of abdominal wall or uterine ligaments. ${ }^{2}$ Uterine torsion is a potentially life threatening condition and may cause irreversible ischemic damage to the uterus, leading to rapid clinical deterioration. ${ }^{3}$ Thus early and accurate diagnosis is essential for its effective management.

\section{CASE REPORT}

A 55 years old postmenopausal lady presented to emergency department of Tribhuwan University Teaching Hospital (TUTH) with complaints of gradually increasing distension of abdomen for 5 years and acute onset of pain abdomen for 5 days. Five years back she was diagnosed to have a mass in uterus and advised for surgery but she did not seek further treatment at the time. Five days prior to the presentation to emergency she developed pain lower abdomen which was sudden in onset, later became generalized and also radiated to the back and inner aspect of bilateral thigh. She had three children, all delivered vaginally at home. She had attained menopause 10 years back at the age of 45 years.

At the time of examination, she had pulse rate of 100 beats /minute, blood pressure $160 / 100 \mathrm{mmHg}$, afebrile without pallor or dehydration. Abdomen was distended with a mass occupying whole of the upper and lower region measuring $36 \mathrm{~cm} \times 30 \mathrm{~cm}$, firm in consistency, smooth surface and regular margin with a groove felt on left. Cervix was difficult to visualize with speculum and on bimanual examination, cervix was pulled up and uterus could not be figured out.

The Computed Tomography (CT) scan of abdomen showed approximately $20 \mathrm{~cm} \times 16.8 \mathrm{~cm} \times 32.2 \mathrm{~cm}$ size lobulated mass in pelvis extending up to the level of renal vessels and L2 vertebra inseparable from uterus. Mass was abutting the lower margin of liver and displacing bowels superiorly and bladder inferiorly. Mass showed slight heterogenous enhancement and increased vascularity on contrast administration. Ovaries were not visualized separately and no significant lymph nodes or free fluid noted. Thus the diagnosis of uterine fibroid with possibility of sarcomatous degeneration was made and was admitted in ward for observation.

After pre-operative evaluation, emergency laparotomy was performed. Abdomen was opened via midline vertical incision. Mass of $40 \mathrm{~cm} \times 25 \mathrm{~cm}$ arising from right cornufundal area of the uterus with torsion of uterus at the level of isthmus by $180^{\circ}$ was noted (Figure 1). The mass was bilobed with each lobe measuring $20 \times 25 \mathrm{~cm}$, irregular surface and soft in consistency. (Figure 2) Bilateral tubes were stretched over the mass. The vessels around the isthmus were engorged and tortuous. (Figure $1 \& 3$ ) Total abdominal hysterectomy with bilateral salphingooophorectomy was performed. (Figure 4)

The post-operative stay at hospital was uneventful and she was discharged on $7^{\text {th }}$ post-operative day with advice to follow up with histopathology report. The Histopathology report revealed leiomyoma with atrophic endometrium with chronic cervicitis and unremarkable bilateral tubes and ovaries.

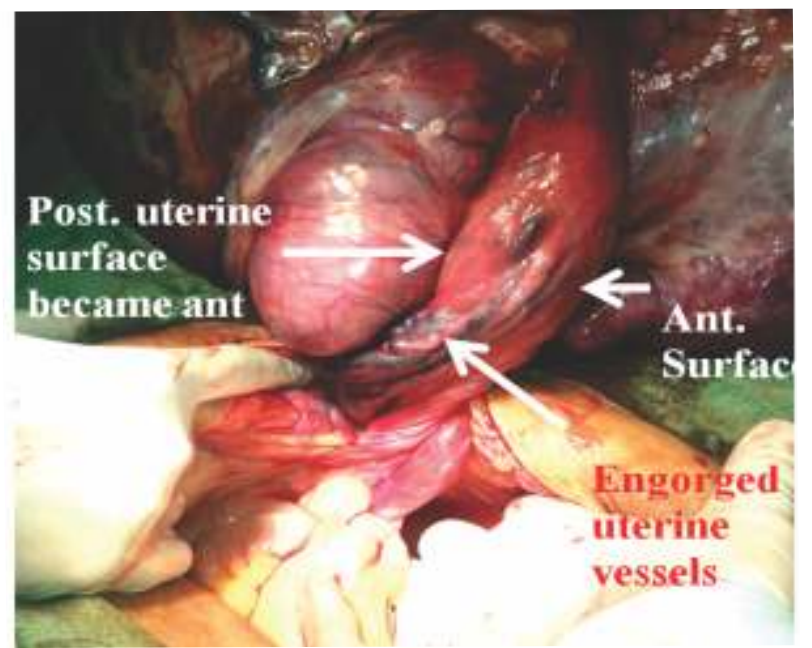

Figure 1: $180^{\circ}$ torsion of uterus at Isthmus

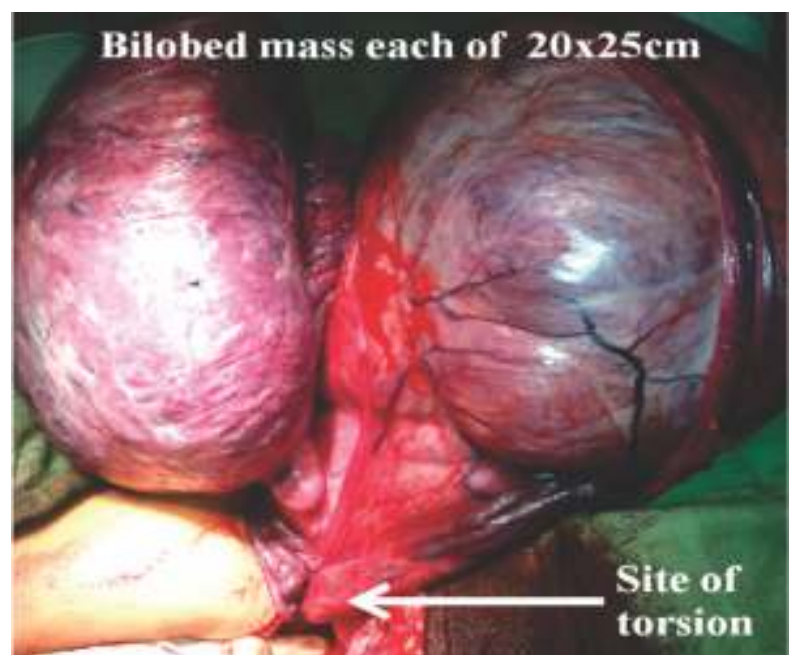

Figure 2: Bilobed mass and the site of torsion

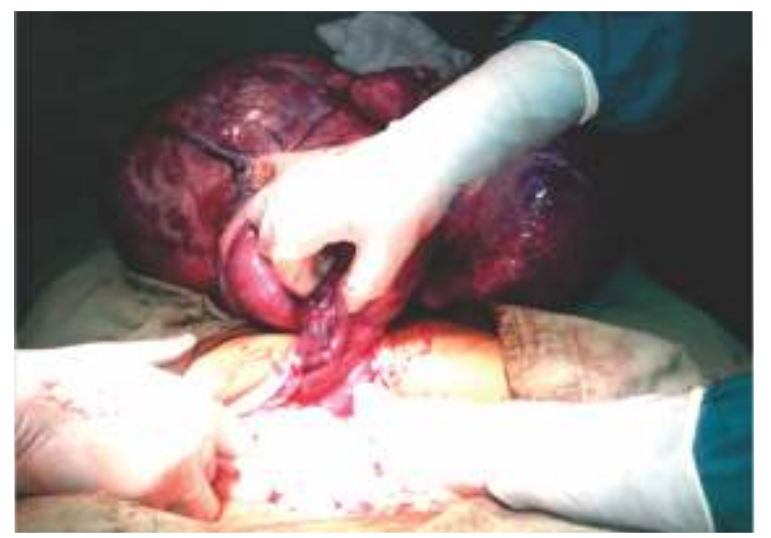

Figure 3: Mass with pulled up isthmus and site of torsion 


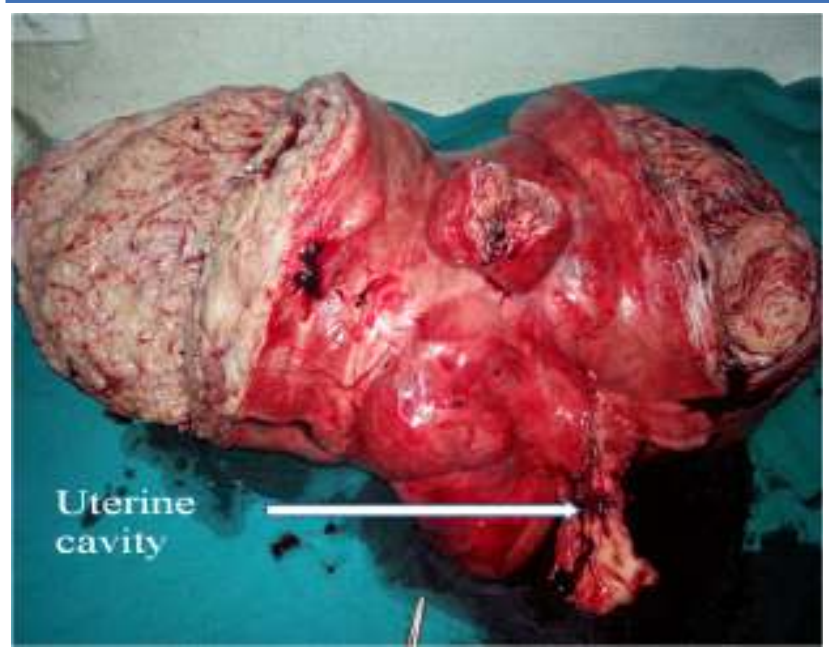

Figure 4: Cut section of the specimen

\section{DISCUSSION}

Torsion of uterus in a non gravid state is a rare clinical entity and was first observed in human at postmortem examination by Virchow in 1863. Less than 300 cases has been reported over last 150 years. ${ }^{4}$ However, in past two decade there is increase in reports of torsion of non-gravid uterus indicating more awareness about the diagnosis and increased preoperative use of advanced radiological imaging techniques. ${ }^{5}$

The mechanism of an axial rotation in a normal uterus is difficult to explain. The uterus in its normal state is firmly held in place by the broad ligaments and the uterosacral ligaments. These supports resist any tendency to torsion. Uterine axial torsion is usually caused by the presence of pathological or abnormal condition in the uterus or the adjacent structures, uterine fibroids being the most common predisposing factor. A large heavy myoma, especially subserosal, fundal myoma, may rotate and exert traction on the uterus. Torsion usually occurs at the level of isthmus. Because of the relatively weak lateral attachment of the body of uterus, it is relatively mobile as compared to well supported cervix via lateral cervical and uterosacral ligaments. ${ }^{6}$

The presentation of uterine torsion ranges from asymptomatic condition diagnosed at the time of surgery to non specific symptoms to acute abdomen and shock. ${ }^{7}$ The associated symptoms may include obstructed labor in cases of gravid uterus, intestinal or urinary symptoms,

\section{REFERENCES}

1. Jensen JG. Uterine torsion in pregnancy. Acta Obstet Gynecol Scand 1992;71:260-5.

2. In: Cunningham FG, Lenovo KJ, Bloom SL, Spong CY, Dashe JS, Hoffman BL, Casey BM, Sheffield JS, editors. Williams Obstetrics. 24 ed. United States: Mc Graw Hill Education; 2014. P

3. Grover S, Sharma Y, Mittal S. Uterine torsion: a missed diagnosis in young girls? J Pediatr Adolesc Gynecol. 2009;22:e5-8.

4. Augustin G. Torsion of the Gravid Uterus. Acute Abdomen During Pregnancy. Switzerland: Springer International Publishing; 2014. p. 529-33.

5. Attapaau JA, Prussia PR, Menon S. Torsion of a non-pregnant fibromyomatous uterus. Int J Gynaecol Obstet. 1994;45:163-4.

6. Hawes CH. Acute axial torsion of the uterus. Ann Surg 1935;102:37-40. abdominal pain as in our case, vaginal bleeding and hypotension. Pre-operative diagnosis of uterine torsion is made difficult by the lack of specific clinical symptoms and signs. However, specific clinical signs including vaginal bleeding, uterine tenderness, a twisted vaginal canal and urethral displacement have been reported. ${ }^{8}$ Various radiological features of uterine torsion have been reported which, if combined with clinical features and high degree of suspicion, help in pre-operative diagnosis of this condition. On ultrasound, change in the position of fibroids from that noted in previous ultrasound scan may indicate torsion of myomatous uterus. Similarly, gas in the uterine cavity on plain radiographs and CT scanning has been described as a feature of uterine torsion. ${ }^{9}$ Magnetic resonance features of uterine torsion have also been described. The wall of the upper vagina changes from the normal $\mathrm{H}$ configuration to an $\mathrm{X}$-shaped configuration in uterine torsion. ${ }^{10}$

Torsion of the uterus may progress to congestion and gangrenous changes in the uterus or adnexae. Because of the rarity of the condition, the critical time after which ischemic change is irreversible is not well documented. ${ }^{11}$ Irreversible ischemic damage to the uterus can worsen patient's clinical condition within a short period of time and pose a serious threat to life. Prompt surgical treatment is necessary to minimize the probability of developing sepsis (related to necrosis) and hemorrhage. In young women of reproductive age, conservative surgical procedures can be done. The anatomical causes of torsion (adhesions, myomas and ovarian cysts) are removed and the uterus is de-rotated to its anatomical position whenever possible. In peri- and postmenopausal women total hysterectomy with salpingoophorectomy is performed as in our patient. ${ }^{8}$

\section{CONCLUSION}

Torsion of a non gravid uterus is a rare clinical event but should be thought as a rare possibility if a women with big myoma or adnexal mass present with features of acute abdomen. Prompt surgical treatment is necessary for avoiding possible fatal outcomes.

\section{CONFLICT OF INTEREST}

None

7. Dua A, Fishwick K, Deverashetty B. Uterine torsion in pregnancy: a review. The Internet Journal of Gynecology and Obstetrics 2006; 6. The Internet Journal of Gynecology and Obstetrics website: number 1 12/article/uterine torsion in pregnancy a review.html. Accessed Nov 2009..

8. Havaldar N, Ashok K. Torsion of non-gravid uterus with ovarian cyst - an extremely rare case. Pan Afr Med J. 2014;18(95).

9. Davies JH . Case report: Torsion of a nongravid nonmyomatous uterus. Clin Radiol. 1998;53:780-2.

10. Nicholson W, Coulson CC, McCoy MC, Semelka RC. Pelvic magnetic resonance imaging in the evaluation of uterine torsion. Obstet Gynecol 1995;85:888-90.

11. Luk SY, Leung JL, Cheung M, So S, Fung S, Cheng SC. Torsion of a nongravid myomatous uterus: radiological features and literature review. Hong Kong Med J 2010;16:304-6. 